\title{
KUHN Y LA RACIONALIDAD *
}

Raúl Alcalá Campos

ENEP ACATLAN - UNAM

\section{Introducción}

La discusión sobre la racionalidad que se ha llevado a cabo entre Kuhn y sus críticos descansa sobre una idea intuitiva de ésta; sin que se haya avanzado en aclarar qué es lo que se entiende por esta noción, por ello la discusión parece caer en los márgenes del no entendimiento; esta falta de entendimiento parece ser un claro ejemplo de la afirmación kuhniana respecto a que científicos de diferentes paradigmas no llegan a un entendimiento por ser sus nociones diferentes.

Por el tipo de críticas llevadas a cabo se podría pensar que estos autores comparten de alguna manera la misma idea sobre la noción de racionalidad, sin embargo, sabemos que Kuhn no acepta que la racionalidad quede reducida a un criterio puramente lógico como parecía pretender el positivismo, ya esto establece una clara diferencia entre estas dos corrientes; pero aún hay más, el positivismo abogaba, en un principio, por que el comportamiento del científico, para considerarlo racional, debería estar enfocado a la verificación de sus leyes y teorías; ante la serie de problemas que esto suscita, se impone un cambio y se adopta el criterio de confirmación, las teorías y leyes no tienen que ser plenamente verificadas, basta con que su confirmación se logre en alto grado. Popper, por otro lado, piensa que el científico no debería dedicarse a verificar sus teorías y leyes sino más bien a falsarlas; en la superación de obstáculos la teoría mostrará su temple. Kuhn, por su parte, niega que la teoría se acepte por su verificación o por la superación de obstáculos únicamente; él propone otros criterios.

La finalidad de este ensayo es realizar una discusión de la noción de

* La realización de este trabajo fue posible gracias a las facilidades dadas por el Programa de Investigación de la ENEP-ACATLAN. Agradezco también al Dr. León Olivé y al Dr. Wonfilio Trejo, quienes leyeron la primera versión de este ensayo e hicieron valiosas críticas. Desde luego cualquier error sólo es atribuible a mí y a nadie más. 
racionalidad que nos permita describir los criterios para la aplicación de ésta ante la conducta de los cientificos y, una vez establecido esto, analizar la posición de Kuhn para ver si se sostienen algunas de las criticas que se le han hecho.

\section{El concepto "racionalidad"}

Un estudio analítico sobre el concepto "racional" no parece ser fructífero, pues en el análisis de los conceptos involucrados en la definición parece haber una petición de principio; en otras palabras, cuando intentamos estudiar analíticamente el concepto "racional" nos encontramos con el caso de que los conceptos que lo constituyen suponen de alguna manera la propia noción de "racionalidad", siendo esto así, lo único que se podría decir sobre este concepto es que es un predicado. restringido a los seres inteligentes, es decir, cuando afirmamos " $x$ es. racional", la variable sólo puede ser sustituida por un término cuyo referente sea un ser inteligente; sin embargo, afirmar " $x$ es racional" no implica que las creencias $y$ las acciones de ' $x$ ' sean siempre racionales. En este momento se hace necesario aclarar que el concepto "racional", utilizado como un predicado aplicable a seres inteligentes exclusivamente, no especifica ninguna facultad inherente al ser humano, en este sentido, definir "hombre" como "animal racional" no constituirfa un enunciado analítico, pues en el concepto "hombre" no está incluido. "ser racional". Desde luego se puede definir "hombre" como "ser racional", pero aqui "ser racional" se tomaría como "ser capaz de efectuar razonamientos", y esto no es lo que nosotros estamos entendiendo por "racional".

Siendo esto así, es decir, ya que el ser "racional" no es una facultad" inherente al ser humano aunque sí un concepto predicable de él, al afirmar " $x$ es racional" $y$ sustituir la variable por el nombre de algún ser inteligente, digamos Ambrosio Velasco, de tal manera que obtengamos el enunciado "Ambrosio Velasco es racional" no es suficiente para predicar verdad o falsedad de dicho enunciado, es necesario especificar bajo qué situación se predica que el ser inteligente Ambrosio Velasco es racional. Esto será aclarado posteriormente.

Si la racionalidad no es una facultad, entonces ¿qué es? Mosterín da la siguiente respuesta: "La racionalidad —en el significado en que aquf la entendemos- no es una facultad sino un método. Pero ninguna facultad garantiza que se aplique el método racional. $Y$ si bien sólo tiene sentido calificar de racional o irracional la conducta de seres inteligentes, según que utilicen o no su inteligencia conforme a las normas del método racional es preciso reconocer que la más aguda de las. 
inteligencias es perfectamente compatible con una crasa irracionalidad." Nótese que Mosterín califica de racional o no la conducta de los seres inteligentes no a los seres inteligentes mismos. Tenemos, pues, dos características de la racionalidad:

1. Se predica de la conducta de seres inteligentes ante ciertas situaciones $y$,

2. no es una facultad sino un método.

Por otro lado, parece no tener sentido hablar de reflexividad de la racionalidad en un ser inteligente alejado de todo contacto social, si fuese el caso que se pudiese hablar de racionalidad de un ser inteligente aislado, podríamos entonces afirmar universalidad en la racionalidad, pero ya León Olivé mostró lo inadecuado de esto, aunque habría que distinguir la universalidad de la "racionalidad" de la universalidad de los criterios de racionalidad, estos últimos son condición de conocimiento de toda sociedad, en este sentido son universales, aunque los criterios no sean los mismos para toda sociedad. De aquí que tengamos que decir que la racionalidad es un predicado aplicable socialmente, pues nos remite a conductas ajenas. Dice Luis Villoro:

Considerar las conductas como fuentes de información responde a un interés vital. Al igual que los otros animales, el hombre requiere que su conducta sea exitosa, es decir, que satisfaga sus necesidades y cumpla sus propósitos. A diferencia de los otros animales, tal vez, necesita además comprender el sentido de su vida y de su mundo para sentirse seguro y orientarse en él. El éxito de su acción y la comprensión del sentido sólo tienen una garantía: la adecuación de su práctica al mundo real, no al de sus fantasías e ilusiones personales, sino al que comparte con todos los hombres. Éxito y sentido de la vida dependen de que nos dejemos guiar por lo que el mundo es realmente. $Y$ esto podemos leerlo en la conducta ajena. Porque el hombre es un animal social en constante convivencia con los demás, las acciones de los-otros pueden revelarnos hechos y objetos del mundo de los cuales no nos percatamos personalmente y que requerimos tomar en cuenta para adecuar nuestra acción a la realidad. ${ }^{2}$

Aunque Villoro utiliza esto como antecedente para su comprensión de la creencia, no de la racionalidad, pensamos que se puede extender a esta última. Por otro lado, León Olivé acepta cierta universalidad que atañe a la racionalidad, pero esta universalidad se otorga en las opera-

1 Mosterín, J., Racionalidad y acción humana. Alianza Universidad, Madrid, p. 17.

2 Villoro, L., Creer, saber, conocer. Siglo XXI, México, p. 58. 
ciónes de verificación y falsación como condición de posibilidad de supervivencia de una comunidad, es decir, una sociedad sobrevive porque existen operaciones, que son realmente universales, que permiten la verificación o falsación de enunciados expresados en el lenguaje de la sociedad en cuestión, sin embargo, las concepciones sobre verificar o falsar pueden ser diferentes en cada sociedad.

Así pues, respecto de la "racionalidad" tenemos: primero, se predica de la conducta y de creencias de seres inteligentes; segundo, no es una facultad sino un método; tercero, su ocurrencia es social; cuarto, no es universal -aunque existen ciertas operaciones, que atañen a la racionalidad, que pueden considerarse como universales en el sentido de condiciones de posibilidad para la sobrevivencia de una sociedad.

\section{Racionalidad creencial y racionalidad práctica}

Respecto a la racionalidad creencial escribe Mosterín, “... diremos que creemos racionalmente que $\psi$ si (1) creemos que $\psi$ y (2) estamos justificados en creer que $\psi . "{ }^{\prime \prime}$ Lo que no exigimos es que $\psi$ sea verdadera, de tal manera que podemos creer racionalmente en algo y sin embargo estar totalmente equivocados. Así, la fuerza de la creencia racional recae sobre el punto (2), es decir, sobre la justificación que se dé para sostener la creencia en $\psi$, Mosterín propone cinco maneras de llevarla a cabo:

1. por ser $\psi$ una idea analítica,

2. por comprobación directa y personal de $\psi$,

3. por estàr vigente en la ciencia actual,

4. porque hay testimonios fiables de $\psi$,

5. porque $\psi$ no contradice otras creencias de $\mathbf{x}$.

Dejando de lado la crítica que Olivé le hace a Mosterín de que está cayendo en una petición de principio al aceptar sin crítica alguna la racionalidad científica, así como tomando como no problemáticas las nociones de verdad, analiticidad, deducibilidad, etc., nosotros encontramos que estas maneras pueden converger en una creencia racional, es decir, que se puede sostener $\psi$ por comprobación directa y personal de $\mathrm{x}$ a la vez de estar vigente la ciencia actual, así como que $\psi$ no contradice otras creencias. La aplicación de estas cinco maneras no basta, a nuestro parecer, para justificar la creencia racional en $\psi$ a menos que se afirme que gran parte de nuestra historia se asentó en creencias irracionales, particularmente la ciencia; pensemos, por ejemplo en la teoría

3 Mosterín, op. cit., p. 19. 
del éter, exceptuando el punto tres parece que no era sostenible por lo restante; aquí surge un problema, ¿por qué la ciencia actual sostiene $\psi$ ?, parece que la respuesta adecuada descansaría sobre los puntos restantes.

Ahora bien, pienso que podemos justificar una creencia racional en $\psi$ cuando ésta es una respuesta a un problema y no contamos con respuestas alternativas adecuadas a la situación, o bien cuando hay alternativas aceptables pero que todas carecen de una buena justificación. Aquí quedan dos caminos: olvidarnos del problema y enfocar nuestros intereses a otros campos de estudio, o adoptar alguna de las teorías alternativas y trabajar con ella confiando en que es la respuesta adecuada, es decir, buscar su justificación, pero mientras esto se logra no parece aceptable decir que el cientifico que aboga por esto último tiene una creencia irracional, aun cuando no cuente con ninguna de las cinco maneras propuestas por Mosterin.

Todo lo anterior nos lleva a pensar que un sistema racional creencial no es algo que se pueda mantener de una manera constante e inalterable, sino que, más bien, es algo que se modifica constantemente gracias al proceso de las creencias. La modificación de un sistema racional creencial puede tomar alguno de los tres caminos siguientes, primero, nuevos casos que justifican aún más nuestra creencia en algo; el descubrimiento de Neptuno significó no sólo el descubrimiento de Neptuno, significó no sólo el descubrimiento de un nuevo planeta, sino además un justificante que garantizaba la gran confianza depositada en la teoría de Newton. Segundo, nuevos casos que van mermando cada vez más nuestras creencias: una teoría bien asentada puede sufrir en sus cimientos cuando aparecen ciertos casos que son de su competencia pero que no puede explicar; el descubrimiento de las fases de Venus, de los satélites de Júpiter, etc., fueron poco a poco modificando la creencia en el sistema aristotélico-tolemaico. Tercero, la necesidad de modificar alguna parte de una teoría por la aparición de ciertos fenómenos que no recogía ésta; en este caso se sigue confiando en la teoría como algo general, pero los ajustes hechos indican algún grado de desconfianza en nuestra creencia; la teoría del flogisto y las modificaciones que sufrió son un ejemplo de esto. En relación con esto dice Mosterín:

Para que la ciencia pueda mantenerse y progresar es necesario que los científicos, como individuos, sean racionales en al menos una porción de sus creencias, a saber, en sus creencias referentes al objeto de su investigación. $Y$ para que los individuos puedan ser racionales en el sentido arriba indicado es necesario que exista una ciencia viva de la que ellos saquen -o, al menos, estén dispuestos a sacar una gran parte- probablemente la mayor parte de sus opiniones acerca del 
mundo. $\mathrm{Y}$ así como vimos que los progresos y cambios en el desarrollo de la ciencia repercuten en cambios en el sistema creencial de los individuos racionales, así también está claro que los cambios en las creencias racionales de los cientfficos -motivados, por ejemplo, por nuevas comprobaciones directas de hechos, por nuevas teorias o por nuevos testimonios fiables - repercuten en cambios en las creencias científicas, que están sometidas a constante revisión. ${ }^{4}$

Así pues, un sistema racional creencial se mantiene porque se cuenta con un justificante para ello, ${ }^{5}$ pero este sistema no es estático sino que puede irse modificando al sufrir cambios las teorías que lo componen.

Por otro lado, señala Luis Villoro, a la pregunta "¿por qué se cree que p?" se le puede responder de tres maneras: por los antecedentes (la génesis de la ciencia), por los motivos supuestos y consecuencias psicológicas y por las razones (relaciones entre creencias de $\mathrm{S}$ y otras creencias). Las tres deben conjugarse para darse la creencia:

Toda creencia tiene necesariamente antecedentes biográficos, puesto que fue adquirida, motivos, puesto que forma parte de una estructura psíquica y cumple una función en ella, y razones, puesto que consiste justamente en tener por existente el objeto de la creencia. Cualquier creencia puede ser explicada de esas tres maneras. ${ }^{6}$

La que nos interesa a nosotros es la última pues es la que apela a justificaciones. Dar razones, según Villoro, es establecer las ligas de la determinación de la acción de un sujeto por la realidad. Justificar es dar razones de las cuales el sujeto derive su creencia, la justificación es un estado disposicional, es una actividad, un proceso, una operación reflexiva.

Las razones a su vez pueden ser explícitas o implícitas, las primeras se hacen presentes cuando se reflexiona en una creencia y se la justifica, las segundas se solicitan cuando la creencia se vuelve reflexiva, pero podemos mantener la creencia sin hacerla reflexiva. Estas últimas se dividen a su vez en tres clases:

1. Procesos causales que originan la creencia, por ejemplo, la percepción, el recuerdo, etc.

2. Razones que nos motivaron para la adopción de una creencia pero que hemos olvidado.

3. Principios generales que sustentan nuestro sistema de creencias de una manera confusa.

4 Ibid., p. 24.

5 La falta de una alternativa mejor puede servir de justificante para la adopción de una teorla que no esté lo suficientemente cimentada.

6 Villoro, op. cit., p. 75. 
Lo que quiere señalar el profesor Villoro es que podemos mantener una creencia sin dar razones explícitas de su aceptación.

Por otra parte, nos vemos en la necesidad de aceptar la existencia de un límite en el proceso de fundamentación de nuestras creencias, en este caso apelamos a lo que el profesor Villoro llama razones básicas, éstas pueden ser de dos tipos, creencias que no se ponen en cuestión para evitar un regreso al infinito, es decir, que aceptamos por considerarlas suficientes; y razones que ya no son creencias porque no podemos dar razones para sostenerlas, sino que son datos presentes a los sentidos; por ello es que se dice que ya no son creencias, pues en los datos de los sentidos no se cree sino que se padece, no decimos "creo rojo", en cambio sí afirmamos "veo rojo"; otro tipo de razones básicas se da en el conocimiento analítico en donde los axiomas y las definiciones son aceptados por estipulación, no son ni verdaderos ni falsos sino condiciones establecidas para el uso de símbolos.

En resumen, no hay creencias de las que no podamos dar razones. Estas razones pueden ser otras creencias, o razones últimas por cuya razón carece de sentido preguntar. Las razones últimas ya no son creencias; pueden ser la recepción de un estímulo (en el conocimiento empírico) o el establecimiento de condiciones para un lenguaje (en el conocimiento analítico). ${ }^{\text {? }}$

Pasemos ahora a estudiar la racionalidad práctica. En cuanto a ésta dice Mosterín “... proponemos precisar el concepto de racionalidad práctica del siguiente modo: Diremos que un individuo $x$ es racional en su conducta si (1) $x$ tiene clara conciencia de sus fines, (2) $x$ conoce (en la medida de lo posible) los medios necesarios para conseguir esos fines, (3) en la medida en que puede, $x$ pone en obra los medios adecuados para conseguir los fines perseguidos, (4) en caso de conflicto entre fines de la misma línea y de diverso grado de proximidad, $x$ da preferencia a los fines posteriores $\mathrm{y}(5)$ los fines últimos de $\mathrm{x}$ son compatibles entre sí." ${ }^{8}$ Lo que me preocupa de esto es que alguien que no cumpla con los requisitos señalados puede ser tachado de irracional, es decir, no me preocupa tanto lo que implica afirmar que alguien es racional en su conducta (lo que implicaría es que cumplió con los cinco requisitos), sino más bien el afirmar que, dado que este alguien no cumplió con los cinco requisitos, entonces es irracional en su conducta. Por ejemplo, tomemos la condición (1), la historia de la ciencia nos habla de algunos

7 Ibid., p. 87.

8 Mosterín, op. cit., p. 30. 
científicos que lograron descubrimientos notables que no se encontraban entre las metas fijadas por la investigación, en otras palabras, es posible que un científico tenga clara conciencia de sus fines $y$, sin embargo, llegue a otra cosa totalmente diferente de la perseguida; el descubrimiento de la droga LSD, o incluso el descubrimiento de América por Cristóbal Colón, se pueden tomar como ejemplos; ¿podemos decir que el comportamiento de estas personas fue irracional? o más bien lo que importa es tener clara conciencia de los fines aunque no se llegue a ellos.

Tomemos ahora la condición (4), Mosterín pone el siguiente ejemplo para ilustrarlo: si se quiere ganar la guerra no hay que acabar las fuerzas en alguna de las primeras batallas. Pero uno no puede seguir esa recomendación como un dogma: cuando los fines posteriores sólo tienen plausibilidad porque se consiguen los fines inmediatos la situación cambia; por ejemplo, ante la posibilidad de concursar por una plaza de medio tiempo en la UNAM uno puede agotar sus fuerzas con miras a obtener el título profesional para cubrir los requisitos indispensables para su participación, es posible que la creación de la tesis y el examen profesional agoten lo suficiente al participante de tal manera que en su trabajo para el concurso no se refleje toda su capacidad intelectual, y sin embargo es completamente válido agotar las fuerzas en la primera batalla; sin el éxito de ésta no tendría sentido la segunda pues la condición de posibilidad de la segunda es la primera.

Por otra parte, existe una estrecha relación entre la racionalidad práctica y la creencial, esta última es un componente de la primera, siendo la relación asimétrica, es decir que la racionalidad práctica presupone la racionalidad creencial, pero no al revés. "La racionalidad de nuestras creencias no implica la racionalidad de nuestras acciones, pero no podemos actuar racionalmente en un campo determinado si no somos racionales al menos en nuestras creencias referentes a este campo." 9

Villoro en cambio nos dice que la racionalidad práctica, en sentido general, cumple dos requisitos, es una actividad intencional, consciente, dirigida por fines, y en este sentido no se refiere a toda actividad humana; su referencia son acciones objetivas y no actos mentales, es decir, que se aplica a comportamientos observables por cualquiera. Distingue también entre la práctica tal y como la hemos expresado, y la noción más estrecha que de ella tiene, digamos el marxismo como actividad transformadora de la realidad, pues no toda actividad humana puede considerarse como transformadora de la realidad; la observación de un partido de futbol, por ejemplo, ¿qué realidad transforma?

Por otra parte, apoyándose en Marx, Villoro sostiene la práctica como o Ibid., p. 31. 
un criterio de verdad; si la acción de un sujeto está motivada por una creencia, y hay un acierto en la acción, resulta que el objeto que motiva la acción es real y por tanto la creencia es verdadera; éste es pues un criterio de verdad condicionado por la acción.

\section{Revision final de las racionalidades práctica y creencial}

Parece haber una correspondencia entre la racionalidad creencial que propone Mosterín y las razones que se tienen para creer que propone Villoro. Aquí hay que distinguir entre lo que el primero llama método y el segundo proceso. Podemos tomar como método la racionalidad y como proceso la justificación, es decir, la creencia de un sujeto puede ser tomada como racional, si puede justificarse objetivamente, pero la justificación puede llevarse a cabo por varios caminos. Aquí corremos el peligro de hacer muy extensa la aplicación del concepto "racional" pues no parece muy complicado encontrar razones que justifiquen cualquier creencia; en otras palabras, una persona que se comporte de manera extraña ante el cruce de un gato por su camino, puede aducir razones para sostener su creencia en la mala suerte que traen los gatos y sobre todo si son negros, puede apelar a la tradición, o a la magia, o incluso a su experiencia pasada: hace algún tiempo se cruzó un gato negro en mi camino y al poco tiempo perdí el empleo. Sin embargo, muy pocos sostendrían que la creencia de tal persona es racional. El camino quc queda, pues, es el de no aceptar cualquier justificación sino sólo aquellas que tengan un carácter objetivo, o sea, constatable por cualquier otra persona; así como que se pueda establecer una conexión lógica entre las razones y la creencia, se puede constatar objetivamente la pérdida del empleo así como el cruce del gato, pero no parece haber ninguna conexión lógica entre una y otro.

Las cinco maneras que propone Mosterín para justificar una creencia son aceptables pero no deben ser tomadas dogmáticamente, aunque tendríamos que agregar aquella que nos permite afirmar cierta razón por no haber ninguna otra más adecuada. La racionalidad es histórica en el sentido de que podemos decir que ciertas sociedades practicantes de la magia tienen una creencia racional en su explicación del mundo que les rodea porque no tienen una explicación más satisfactoria; nadie puede decir que el criterio de racionalidad dado aquí y ahora es, fue y será el único. Mosterín señala muy bien esto con los siguientes ejemplos: "Asi, hoy resulta racional que creamos que el sexo de los infantes sólo depende del padre y no de la madre, pero hace dos siglos esa misma creencia no hubiera sido racional. A la inversa, hace dos siglos hubiera 
sido racional creer en la validez de las leyes de Newton, pero hoy ya no lo es." 10

Lo que hemos querido apuntar es que, en tanto el criterio de racionalidad es histórico, podemos sostener una creencia, que sería irracional para nosotros dada nuestra cultura, como racional ubicándola en su contexto, en su momento histórico y dadas las circunstancias que le rodean. Este carácter de la racionalidad es lo que impide, también, la justificación total de todas nuestras creencias; las razones básicas que subyacen al sistema creencial también pueden variar; si tomamos como razones básicas nuestros datos de los sentidos, lo que observamos, resulta que esto está cargado del lugar donde nos paremos, es decir, las observaciones se realizan desde una teoría; siendo las teorías históricas, las observaciones también lo serán, esto ya ha sido apuntado por Hanson. ${ }^{11}$

Pasemos a la racionalidad práctica. A diferencia de la racionalidad creencial, en donde bastaba que se diera uno de los cinco caminos apuntados para considerar la creencia como racional, tenemos cinco pasos que se deben cumplir necesariamente para que un comportamiento sea tomado como racional según Mosterín.

Debemos encontrar un camino que. nos lleve a sostener el comportamiento de un individuo como racional teniendo en cuenta sus fines, y que evite el problema que apuntamos cuando vimos este caso (poder tener clara conciencia de los fines y, sin embargo, llegar a otro lado). El mismo problema se presenta en Villoro cuando define la racionalidad práctica como una actividad intencional, conciente, dirigida por fines. El camino parece ser el de aprovechar la relación asimétrica entre la racionalidad práctica y la creencial. Esta última está presupuesta en la primera pero no al revés. Bien, lo que tenemos es, en la racionalidad práctica, un individuo $x$ que tiene clara conciencia de sus fines, pero esto descansa en un sistema de racionalidad creencial; la conciencia del fin perseguido se sostiene por un conjunto de creencias. ¿Qué se quiere decir con tener clara conciencia? Parece que el sentido que se le da a esta expresión va por dos caminos: primero, tener suficientemente claro en la mente lo que se quiere lograr, y, segundo, que el fin perseguido es de hecho realizable.

Si bien el primer sentido es un proceso mental no justificable, es decir, no es una creencia, el segundo sí lo es, la realización o no del fin perseguido puede modificar nuestra creencia y llevarnos por otro camino. Nuestra meta es encontrar las evidencias de la existencia del éter; creamos los medios adecuados (el experimento de Michelson-Morley), los llevamos a la práctica y nos encontramos con que lo que espe-

10 Ibid., p. 21. Aunque creo que en este último ejemplo exagera.

11 Cfr. Hanson, N. R., Patrones de descubrimiento. Alianza Universidad, Madrid. 
rábamos no ocurre, revisamos el experimento y lo realizamos varias veces y el resultado esperado no ocurre; el camino que resta es negar que la meta perseguida sea realizable, es decir, que nuestra creencia en la existencia del éter es errónea. Pero no podemos decir que nuestro comportamiento es irracional por no obtener los fines perseguidos. Si bien la racionalidad práctica presupone la racionalidad creencial, esta última puede ser modificada por la primera.

Lo que tenemos, pues, es lo siguiente, la racionalidad puede ser de dos tipos: creencial o práctica. La primera consiste en la creencia en algo, y la justificación de dicha creencia; la segunda incluye como componente a la racionalidad creencial y apela a un criterio de verdad práctico. Hay que hacer notar que aunque tomamos en general las concepciones de Villoro y Mosterín en cuanto a la racionalidad, sus criterios han sido ampliados para evitar los problemas apuntados anteriormente. Tómese en cuenta que nosotros sostenemos los criterios de racionalidad como un componente socio-histórico, dependientes del contexto y no como un rasgo a priori del ser humano.

Veamos si esto es adecuado para una interpretación del pensamiento de Kuhn.

\section{Kuhn y la racionalidad (Primera Parte)}

En este inciso nos proponemos hacer uso de todo lo anterior partiendo de dos premisas principales, (1) el reconocimiento de la práctica científica como la expresión máxima de la racionalidad y (2) la idea de Kuhn de modificar el concepto de racionalidad. El reconocer la primera premisa implica que no podemos dar unas condiciones a priori de la noción de racionalidad; lo que se pretende es expresar la conducta de los cientificos como manifestación de racionalidad.

Creemos que tratar de afirmar: "el cientifico tal tiene un comportamiento racional (o no)" no tiene sentido si se trata de aplicar ciertos criterios de la racionalidad de una manera apriorística, aislando al científico de su contexto; es decir, hemos aceptado la historicidad de los criterios de racionalidad además de su socialización, de aquí que no baste decir "el cientifico tal tiene un comportamiento racional o no"; para afirmar la verdad o falsedad de este enunciado, tenemos también que decir desde qué contexto histórico se hace tal afirmación asi como en qué sociedad se ubica al científico.

La idea central que defendemos es que los criterios de racionalidad científica no deben ser aplicables a un individuo sin más, sino que son aplicables a las comunidades cientificas, y por ende a los individuos pertenecientes a dichas comunidades. Las comunidades cientificas son 
las que estipulan los criterios de racionalidad que regirán el comportamiento de sus integrantes; de un individuo que no se comporte de acuerdo a estos cánones puede decirse que su comportamiento es irracional si forma parte de la comunidad en cuestión; que es irracional si no pertenece a la comunidad, por lo que no tiene por qué saber las reglas; o bien que es un revolucionario si intenta modificar los cánones. Esta idea no es nueva, ya se encuentra en Kuhn aunque no de una manera desarrollada, dice éste: "La ciencia no es la única actividad a cuyos practicantes se les puede agrupar en comunidades, pero es la única en cada comunidad, es su propio y exclusivo público y juez." 12

El comportamiento de un científico, o más bien la cualificación del comportamiento, queda así determinada según los cánones de la comunidad en cuestión. Un "científico" perteneciente a una "comunidad científica" de la edad media vería sospechoso el comportamiento de los científicos actuales ante el problema de la estructura del ADN, y los seguidores de la comunidad científica que tratan este problema no podrían adjudicarle a aquél un comportamiento irracional, ya que no conoce las reglas del juego de la comunidad última. Incluso aquí es donde se observa más claramente la inconmensurabilidad. Independientemente de la revolución o no de Copérnico o de Galileo, cuando este último proponía un método experimental estaba abogando por que el comportamiento del científico, o bien las creencias del científico, deberían estar guiadas por la experimentación y no por un criterio de autoridad; estaba proponiendo una norma para un comportamiento racional. La falta de comunicación con los aristotélicos estribaba en que el criterio de éstos era diferente al de Galileo, el rechazo a la observación a través del telescopio no obedecía tanto a lo que se pudiera observar como al rompimiento con una norma, la ciencia es producto, por un lado, del estudio de las obras de Aristóteles y, por el otro, de las sagradas escrituras. Cada uno de los integrantes de su comunidad podría decir que los integrantes de la otra no participaban de su juego, pero no los podría tachar de irracionales por ello. León Olivé ha señalado la no universalidad de la racionalidad pero afirma una universalidad de la necesidad de los criterios aun cuando éstos no sean los mismos:

Conceptos como los de verdad, validez, corrección aluden a marcos categoriales, presupuestos por toda acción e interacción social. Esos marcos se sustantivizan en contextos culturales específicos acompañados necesariamente de criterios de identificación, según los cuales es posible decidir el apego o conformidad, o bien el quebrantamiento

12 Kuhn, T. S., "Consideración en torno a mis críticas", en Lakatos y Musgrave (eds.), La critica y el desarrollo del conocimiento. Grijalbo, México, p. 420. 
de la norma en cuestión, la racionalidad o irracionalidad de la acción, etc., si bien los actores pueden no estar concientes de todos los criterios. Los criterios son siempre dependientes de un contexto, lo cual no veo que tenga que impedir que puedan ser identificados y resultar inteligibles para miembros de otras culturas. De lo que se puede predicar universalidad es, entonces, de la necesidad de cierto tipo de categorías, y también de la necesidad de que vayan acompañadas de ciertos criterios de decisión. Pero la forma en que sustantivizan los conceptos y los criterios depende de cada contexto. ${ }^{13}$

De aquí que la validez de los criterios en la ciencia de la edad media y la propuesta por Galileo sean diferentes. Si bien los dos persiguen la verdad en sus enunciados, en uno sus criterios se establecen por la conformidad con las obras de Aristóteles, mientras que en el otro se apela a la naturaleza.

Por otro lado, puede ser el caso que se acepten las normas que rigen a la comunidad y, una vez aceptadas, se rompan; aquí se presentan dos alternativas: primero, se rompen las normas sin proponer otras, lo cual nos lleva a plantear como irracional el comportamiento de tal sujeto; segundo, se rompen las normas pero se proponen otras, lo cual ya no es irracional sino revolucionario. La crítica destructiva sin proponer una opción nos lleva al caos. Einstein destruye la manera newtoniana de enfrentarse al mundo, pero al mismo tiempo propone una nueva visión. El destruir un sistema de gobierno nada más por el afán de destrucción no soluciona los problemas sociales que se tenían, sino al contrario, los incrementa si no se propone otro sistema más adecuado a la realidad social existente. Esta es también la posición de Kuhn cuando afirma que una teoria no se abandona, aun con todos los problemas que presente, si no se tiene una alternativa, en caso contrario los científicos que destruyen la teoría vigente tendrían un comportamiento irracional.

Nótese que dos comunidades científicas que usan diferentes visiones del mundo pueden sostenerlas como inconmensurables $y$, sin embargo, establecer un punto de comunicación a través de los criterios que Olivé sostiene como universales, es decir, se puede sostener que ambas comunidades mantendrían que el interés primordial de la ciencia es la persecución del conocimiento, en el sentido de enunciados verdaderos, y sin embargo diferir en los criterios para verificar los enunciados, pero esto no impide una comunicación acerca de qué criterios son los más adecuados.

En última instancia los criterios de racionalidad muy rara vez son aclarados por los científicos, los interesados por estos problemas son los

13 Olivé, L., "Sobre la determinación social de la racionalidad", Diánoia No. 27. UNAM, México, p. 15. 
filósofos; para poner un ejemplo drástico podemos ver la propuesta de Carnap y sus seguidores, donde lo que se persigue es confirmar un sistema de enunciados (una teoría), en tanto que en Popper y su escuela el comportamiento racional de un científico consiste en falsar el sistema de enunciados. Pero nótese que la discusión entre estas dos corrientes descansa en las ventajas o desventajas de los criterios.

Los criterios de racionalidad deben aceptarse, pues, por convención considerando que son los adecuados para la práctica científica. Dice Popper: "En la presente obra consideramos las reglas metodológicas como convenciones: las podríamos describir diciendo que son las reglas del juego de la ciencia empírica." 14 Nosotros podriamos poner, donde dice "reglas metodológicas" "criterios de racionalidad" y los describiríamos como las reglas del juego racional de la ciencia empírica para una comunidad cientifica.

Bien, lo que tenemoś es, pues, que los criterios de racionalidad son dinámicos, varían con el desarrollo cultural de una comunidad, varían también de comunidad a comunidad, de tal manera que al hablar del comportamiento racional o no de algún cientffico se debe apuntar con respecto a qué comunidad; además, los criterios de racionalidad se aceptan por convención, no es posible decir cuáles de los criterios son los verdaderos, pero sí cuáles son los más aceptables dada la carga cultural que se tenga. Incluso Carnap intuía algo de esto, aunque no lo desarrolló totalmente, cuando afirmaba que no es lo mismo lo que los cientificos consideran como observable que lo que consideran como tal los filósofos, los criterios para aceptar algo como observable varía de unos a otros.

\section{Comunidades científicas}

El afirmar que los criterios de racionalidad varían de comunidad a comunidad nos obliga a realizar un análisis sobre éstas. Kuhn define una comunidad científica como aquella que comparte un paradigma, pero reconoce una circularidad pues toma un paradigma como aquello, que comparte una comunidad cientifica. "Un paradigma es lo que comparten los miembros de una comunidad científica y, a la inversa, una comunidad cientifica consiste en unas personas que comparten un paradigma." ${ }^{15}$ Sin embargo plantea que las comunidades científicas pueden reconocerse sin tener que identificar antes al paradigma, pero también reconoce que en la Estructura de las revoluciones cientificas maneja una noción intuitiva de ésta, aunque intenta aclararla en la posdata.

14 Popper, K., La lógica de la investigación cientlfica. Tecnos, Madrid, p. 52.

$15 \mathrm{Kuhn}, \mathrm{T}$. S., La estructura de las revoluciones cientificas. FCE, México, p. 271. 
Nosotros, sin embargo, tomaremos como base las ideas de Villoro sobre comunidades epistémicas. Este autor considera que cuando un sujeto aduce ciertas razones para sostener una creencia, éstas serán objetivamente suficientes si, para alguna otra persona, son suficientes en tanto tenga acceso a los mismos datos, se encuentre en el mismo marco conceptual y esté entrenado para comprender las razones teóricas que se argumentan. El ejemplo que maneja versa sobre el conocimiento de Kepler respecto a las órbitas de los planetas; las razones dadas por Kepler sólo serán comprendidas por las personas que tengan acceso a los datos de observación dados por Ticho Brahe ya que éstos fueron el punto de partida de Kepler; aquí el tener acceso implica una comprensión de los datos así como del manejo de los instrumentos necesarios para corroborar tales datos; se necesita además un conocimiento sobre los fundamentos teóricos que está manejando el investigador, en otras palabras, debe estar familiarizado con el lenguaje de éste; por último, debe compartir ciertas creencias básicas con Kepler que no se encuentran explícitas en el discurso pero que son su sustento, creencias tales como que los planetas son cuerpos materiales y no espíritus, etc. Esto permite a Villoro definir "sujeto epistémico pertinente" así como "comunidad epistémica pertinente"; nos dice: "llamemos "sujeto epistémico pertinente' de la creencia de $S$ en $p$ a todo sujeto al que le sean accesibles las mismas razones que le son accesibles a $\mathrm{S}$ y no otras, y 'comunidad epistémica pertinente' al conjunto de sujetos epistémicos pertinentes para una creencia". ${ }^{16}$ Parece, pues, que tomando un individuo con tales y tales características podemos formar una comunidad estableciendo una relación con todos los individuos que tenían las mismas características que aquél, esto es lo que en teoría de conjuntos se nombra como clases de equivalencia.

A lo que hemos llegado es a comunidades epistémicas que rebasan el campo de la ciencia, es decir, estas comunidades no sólo se encuentran en el ámbito científico sino en cualquier comunidad social; los grupos religiosos, por ejemplo, constituirán comunidades epistémicas. Como nuestra discusión versa sobre comunidades cientificas tendremos que encontrar algunos rasgos que nos permitan distinguir entre comunidades epistémicas cientfficas y cualquier otro tipo de comunidad. Estos rasgos caerán sobre los elementos que relacionan a un individuo con los otros (en otras palabras, caerán sobre el tipo de datos, el tipo de teorias y el tipo de marco conceptual), aunque esto puede ir variando con el transcurso del tiempo y de comunidad a comunidad, sin embargo, parece que las comunidades epistémicas científicas dirigen sus elementos a una meta específica, a saber, la adquisición del conocimiento. Comunidades religio-

16 Villoro, op. cit., p. 147. 
sas, de brujería, de equipos de futbol quedan fuera así de las comunidades epistémicas cientificas. Si bien las comunidades científicas persiguen un conocimiento, saben que éste puede ser superado, y se afanan en su superación, de manera tal que el conocimiento se vuelve dinámico, las comunidades religiosas así como las de brujería se sostienen por actos de fe, nunca se pone en duda si sus creencias son válidas o no, se aceptan por fe exclusivamente; las comunidades futbolísticas no tienen nada de esto, ni persiguen conocimientos ni se establecen por fe en algo, simplemente se forman alrededor de unas reglas que rigen el juego de futbol; si usted quiere pertenecer a la comunidad futbolística apréndase las reglas.

Por otra parte es necesario apuntar que cada comunidad delimita sus horizontes, de tal manera que un individuo se toma como pertinente ante ciertas razones si éstas caen bajo el ámbito de su comunidad, Villoro expresa esto de la siguiente manera:

Cada comunidad epistémica delimita, así un conjunto de razones accesibles, de acuerdo con la información de que puede disponer, con su nivel de tecnología, con el desarrollo de su saber previo y con el marco conceptual básico que supone. Para juzgar la objetividad de una justificación aducida sólo son pertinentes los juicios de los miembros de esa comunidad epistémica porque los demás no están en condiciones adecuadas para juzgarlas. A la inversa, todo sujeto epistémico lo es con relación a un conjunto de razones accesibles $y$, por lo tanto, a un conjunto de creencias. Una persona puede ser sujeto epistémico pertinente con relación a ciertos saberes y creencias y no serlo con relación a otros. ${ }^{17}$

Con esto quedan delimitadas las comunidades epistémicas pertinentes sin necesidad de señalar previamente el paradigma que los gobierna; nos basta con señalar que comparten un paradigma pero no necesitamos hacer un análisis de éste para identificarla.

Lo dicho hasta aquí no altera en nada la posición kuhniana, antes bien la precisa y evita los problemas para comprenderla.

Podemos de alguna manera, guiados por lo anterior, delimitar las comunidades científicas separándolas de las que no lo son y, una vez logrado esto, distinguir entre las diferentes comunidades cientificas la pertinencia de los juicios de sus miembros. Esto está también en Kuhn cuando escribe acerca de una comunidad cientifica como aquella consistente "... en quienes practican una especialidad científica. Hasta un grado no igualado en la mayoría de los otros ámbitos, han tenido una

17 Ibid., p. 148. 
educación y una iniciación profesional similares. En el proceso han absorbido la misma bibliografía técnica y sacado muchas lecciones idénticas de ella. Habitualmente los límites de esa bibliografía general constituyen las fronteras de un tema cientifico, y cada unidad habitualmente tiene un tema propio". ${ }^{18}$

Señala después que existe cierto entramado entre las comunidades científicas, de tal manera que se puede tomar a la comunidad de los científicos naturales como la más grande, estando formada por un conjunto de pequeñas comunidades cientificas: médicos, físicos, químicos, etc., y éstas a su vez estar divididas en físicos cuánticos, relativistas, etc.

\section{Kuhn y la racionalidad (Segunda Parte)}

En su artículo "Notas sobre Lakatos" el profesor Kuhn asume que tanto Lakatos como él se están forzando en cambiar la noción de racionalidad. El tener ciertos criterios de racionalidad tomados a priori, y aplicarlos a una parte de la historia de la ciencia para concluir que los científicos de ese periodo se comportaban racionalmente o no, no parece tener sentido alguno; para Kuhn el proceso debe ser al contrario, hay que partir de la afirmación de que el comportamiento científico es el comportamiento racional por excelencia. Si nos negamos a aceptar el sentido aprioristico de los criterios de racionalidad, debemos buscar una base no a priori que los sostenga, según el autor de la Estructura... la base debe ser tomada de la misma práctica cientifica, de la observación del comportamiento de las comunidades científicas; como ésta no es uniforme a lo largo de la historia de la ciencia, tenemos que concluir que los criterios de racionalidad tampoco; esta consecuencia ya la habiamos apuntado anteriormente. Por lo tanto, el que la práctica científica sea la base para obtener los criterios de racionalidad no implica que los científicos se comporten siempre de una manera racional, una cosa es aceptar un criterio por la práctica cientifica tomada en su conjunto y en su momento, y otra muy diferente aceptarlo tomando como sustento el comportamiento de un científico individual. Alguien podría preguntarse en este momento ‘cómo se obtienen los criterios a partir de la práctica científica?, la única respuesta posible es: analizando el comportamiento de las comunidades científicas epistémicas de determinado periodo histórico. Kuhn lo afirma de la manera siguiente:

... ni por un momento creo que la ciencia sea una empresa intrínsecamente irracional. Sin embargo, lo que quizá no he dejado suficientemente claro es que no considero esa afirmación como una cuestión de

16 Kuhn, T. S., La estructura..., p. 272. 
hecho, sino más bien como cuestión de principio. La práctica científica tomada en su conjunto, es el mejor ejemplo de racionalidad de que disponemos. El hecho de que la consideremos racional depende de manera significativa, aunque desde luego no exclusiva, de cuáles sean los aspectos que tomemos como esenciales de la práctica cientifica. Esto no es lo mismo que decir que todo cientifico se comporta racionalmente en toda ocasión, ni siquiera que muchos de ellos se comportan racionalmente la mayoría de las veces. Lo que se afirma aquí es, si la historia o cualquier otra disciplina empírica nos lleva a creer que el desarrollo de la ciencia depende esencialmente de un comportamiento que previamente hemos considerado como irracional, entonces debiéramos concluir no que la ciencia es irracional, sino que nuestra noción de racionalidad necesita retoques aquí y allá. ${ }^{19}$

Lo que se niega pues, es que exista una racionalidad apriorística, universal y necesaria que se pueda aplicar aquí y allá de manera semejante; este rechazo es también la posición de León Olivé que vimos anteriormente, aunque éste no aceptaría sin una buena justificación la afirmación de que la práctica científica ejemplifica el comportamiento racional por excelencia; ¿por qué la ciencia y no cualquier otra actividad humana?

Desde luego que uno puede concluir que los científicos se comportan de una manera irracional, pero dado el prestigio que la práctica científica ha alcanzado en nuestros días y en vista del rechazo de un criterio apriorístico de racionalidad, tomamos a la ciencia como el modelo a seguir, aunque existe una fuerte tendencia a creer que la actividad científica es completamente racional por sf misma y no porque nosotros la consideremos así. No dudo que si algún indio de la tribu tarahumara estuviera realizando este trabajo tomaría como modelo la actividad de los médicos brujos como criterio de racionalidad.

Para finalizar veamos una de las críticas más fuertes que se le han hecho a Kuhn, la crítica de Dudley Shapere. Este autor parece no estar de acuerdo con algunas afirmaciones de Kuhn respecto a lo que debe ser válido en la ciencia y en su evolución, puesto que no es posible fundamentar tales afirmaciones tomando como premisas los resultados de estudios históricos; lo que en última instancia critica es que Kuhn haga tales afirmaciones teniendo como base hechos ocurridos en el pasado.

Ahora bien, si la finalidad de Kuhn es explicar precisamente la dinámica de los criterios de validez en la ciencia, mostrar que nuestros criterios no son los mismos que los de hace 500 años y por ello afirmar

19 Kuhn, T. S., "Notas sobre Lakatos", en Lakatos y Musgrave (eds.), op. cit., p. 520. 
que lo que ahora es válido es esto y aquello, no queda otro remedio que apelar a la historia.

Shapere parece interpretar las afirmaciones de Kuhn como respuestas a la pregunta "¿Cómo debe ser la ciencia?", es decir, respuesta de la forma "debe ser de tal y tal manera, dado que su evolución histórica fue así y ass". Pero también cabe otra interpretación, aquella que toma las afirmaciones como respuestas a la pregunta "¿Cómo es la ciencia?", las cuales deben ser respuestas del estilo "es de tal y tal manera y debe ser así dado su desarrollo histórico". En la interpretación de Shapere la crítica es adecuada, pero en esta última se debilita.

En la primera pregunta se interroga por el deber ser de la ciencia, en la segunda no, en ésta se interroga por la ciencia en determinado momento, y el estado en que se encuentra está condicionado por su evolución histórica, es una consecuencia de su desarrollo; de otra manera, una cosa es afirmar cómo debe ser la ciencia, como una imposición y apelar a la historia para sostenerlo, y otra muy distinta observar la actividad científica y afirmar "es así dado su desarrollo histórico".

Con este estudio sobre la racionalidad caemos en la cuenta de que las críticas a Kuhn sobre su posición al respecto caen por la borda. Kuhn no propone irracionalidad en la actividad científica, su posición es más radical, lo que defiende es, al contrario, una profunda racionalidad en. ciencia, ella es el modelo a seguir para obtener criterios de racionalidad. Creo que si se le preguntara a Kuhn cuáles son sus criterios de racionalidad respondería: "son los mismos que los de los científicos", o bien, "racional es lo que hacen los cientificos". 